\title{
Long-term follow-up of direct current cardioversion after cardiac surgery with special reference to quinidine ${ }^{1}$
}

\author{
J. F. Gunning ${ }^{2}$, A. Kristinsson ${ }^{3}$, G. Miller ${ }^{4}$, and K. Saunders ${ }^{5}$ \\ From The Unit of Clinical Cardiology, Department of Medicine, Royal Postgraduate \\ Medical School, London W.I2
}

The results of the long-term follow-up of II9 patients who had DC cardioversion performed are described. All patients had had corrective cardiac surgery for chronic rheumatic valvar heart disease. The poor prognosis for maintenance of sinus rhythm in this type of patient is emphasized. Of the total patients, 83 per cent were converted to sinus rhythm, but relapses were common in those who had atrial fibrillation before operation. Only 40 per cent of such patients maintained sinus rhythm for 2 months, 15 per cent for I year, and 9 per cent for 2 years.

By contrast, when atrial fibrillation occurred for the first time in the post-operative period, 82 per cent maintained sinus rhythm for 2 years after conversion.

Post-operative DC cardioversion is in general not recommended for patients with rheumatic heart disease and atrial fibrillation unless atrial fibrillation occurs for the first time in the postoperative period. A controlled trial of prophylactic quinidine is reported and shows no significant increase in the number of patients remaining in sinus rhythm as compared with a control group not receiving quinidine.

The commonest indication for elective cardioversion is the presence of atrial fibrillation after cardiac surgery for chronic rheumatic valvar heart disease. Most papers on the follow-up of patients converted to sinus rhythm include conversion from atrial fibrillation due to other causes, where the prospects of maintaining sinus rhythm may differ. This series contains only patients with chronic rheumatic heart disease with atrial fibrillation after corrective cardiac surgery, and also includes those with atrial fibrillation before operation. The trial was designed to determine the effectiveness of conversion to, and maintenance of, sinus rhythm. The period of follow-up is longer than in most other series and extends to 4 years in some patients. The

Received 13 November 1969.

1 Address for reprints: Professor J. F. Goodwin, Royal Postgraduate Medical School, London W.r2.

2 Present address: Department of Physiology, Mayo Clinic, Rochester, Minnesota, U.S.A.

3 Present address: Landsspitalinn, University Hospital, Medical Department, P.O. Box 1036, Reykjavik, Iceland.

4 Present address: Cardiac Department, Brompton

Hospital, London S.W.3.

5 Present address : Department of Medicine, St. Thomas' Hospital, London S.E.I. haemodynamic advantages of sinus rhythm are well known, but attempts at restoration of sinus rhythm only seem to be indicated if maintenance of normal rhythm could be expected in a high percentage of patients.

There have been few controlled trials on the long-term use of quinidine to attempt to increase the stability of sinus rhythm after cardioversion, and the results have been conflicting. We have, therefore, added the results of our controlled trial of the use of quinidine to maintain sinus rhythm in order to clarify the indications for the use of this potentially dangerous drug.

\section{Patients and methods}

One hundred and nineteen patients undergoing attempts at direct current (DC) cardioversion for atrial fibrillation for the first time at Hammersmith Hospital between August 1964 and August I968 comprise this series. Only patients with chronic rheumatic heart disease were included. The attempt at cardioversion was made between one month and three months after corrective cardiac surgery. The type of preceding cardiac surgery is shown in Table $\mathrm{r}$. Cardioversion was only attempted when the onset of atrial fibrillation was judged to have occurred within the 24 months 
TABLE I Operative proceedures

\begin{tabular}{lc}
\hline Types of operations & No. of patients \\
\hline Mitral valvotomy & 62 \\
Mitral valve prosthesis & 25 \\
Aortic valve prosthesis & I5 \\
Mitral and aortic valve prostheses & 2 \\
Mitral valve repair & 7 \\
Aortic valve prosthesis and mitral & 7 \\
$\quad$ valvotomy & I \\
Aortic valve repair & II9 \\
\hline Total & \\
\hline
\end{tabular}

preceding the operation. All patients were taking anticoagulants at the time of cardioversion, with Quick one-stage prothrombin times of 22-28 seconds. Digitalis was suspended 48 hours before cardioversion. The synchronized Lown DC Cardioverter (American Optics) was used, the patient being under general anaesthesia. A roo joules discharge was used initially, and if unsuccessful 200 and then 300 joules were used, but higher discharges were not employed. The patients were followed at the out-patient clinic for from between 2 months and 50 months, in order to note the incidence of maintenance of sinus after and of reversion to atrial fibrillation.

During the period from August 1965 to August 1968 alternate pairs of patients were placed in 2 groups; with quinidine and without quinidine, respectively. Each patient in the quinidine group was given $0.2 \mathrm{~g}$. quinidine sulphate at $6 \mathrm{p} . \mathrm{m}$. on the evening before cardioversion, and $0.5 \mathrm{~g}$. quinidine bisulphate twice daily was continued for the duration of the trial or until reversion to atrial fibrillation occurred. No change was made in other drug treatment. Quinidine blood levels were not measured as doses of this order have resulted in satisfactory quinidine levels of $\mathrm{I}-4 \mathrm{mg}$./1. in other series (Reinikainen et al., I965; Szekely, Batson, and Stark, I966; Rossi and Lown, 1967; Hall and Wood, r968).

The non-quinidine group received no quinidine treatment, but continued to take their other cardiac drugs.

Beta-adrenergic blocking drugs were not used in either group.

The number of patients initially in the quinidine group was 43, and in the non-quinidine group, 42. The type of cardiac surgery that had been performed in the quinidine and the non-quinidine groups is shown in Table 2.

\section{Results}

The number of patients remaining in sinus rhythm at 2 months, 1,2 , and 3 years, respectively, for the total series of II9 patients is shown in Fig. I. The results are expressed as the percentage of the patients remaining in sinus rhythm to the total followed up for the appropriate time. The unsuccessful conversions are included in the total number for
TABLE 2 Operations and quinidine prophylaxis

\begin{tabular}{lll}
\hline Types of operations & $\begin{array}{l}\text { No. of } \\
\text { patients in } \\
\text { quinidine } \\
\text { series }\end{array}$ & $\begin{array}{l}\text { No. of } \\
\text { patients } \\
\text { in non- } \\
\text { quinidine } \\
\text { series }\end{array}$ \\
\hline $\begin{array}{l}\text { Mitral valvotomy } \\
\begin{array}{l}\text { Mitral prosthesis } \\
\text { Aortic prosthesis } \\
\text { (or homograft) }\end{array}\end{array}$ & 32 & 18 \\
$\begin{array}{l}\text { Aortic prosthesis and } \\
\text { mitral valvotomy }\end{array}$ & 5 & 8 \\
$\begin{array}{l}\text { Mitral repair } \\
\text { Aortic repair }\end{array}$ & 4 & 8 \\
\hline Total & - & 3 \\
\hline
\end{tabular}

each follow-up period, when the date of their attempted conversion would have allowed them to be followed for the time considered. The results at 4 years of follow-up (one of four patients remaining at sinus rhythm) are not shown in Fig. I because of the small number involved.

The results for the two groups, quinidine and non-quinidine patients, are shown in Fig. 2. There were 43 in the quinidine group, and all but 3 were converted to sinus rhythm. There were 42 in the non-quinidine group, one patient died I month after conversion (in sinus rhythm) from post-operative complications, and 7 patients had ceased taking quinidine when seen 2 months after conversion. The latter patients were then added to the nonquinidine group for the purposes of follow-up. In the non-quinidine group 2 patients were lost to follow-up before 2 months. The results are again expressed as the percentage of the

FIG. I Number of patients remaining in sinus rhythm for the total series at various times of follow-up. (The results at 4 years are not shown.)

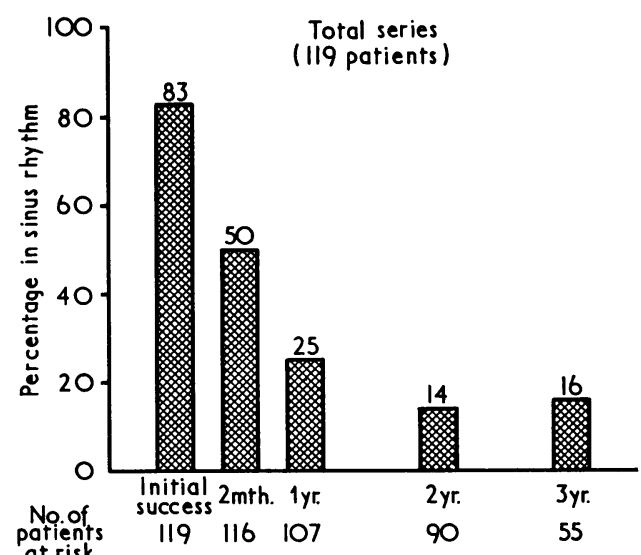



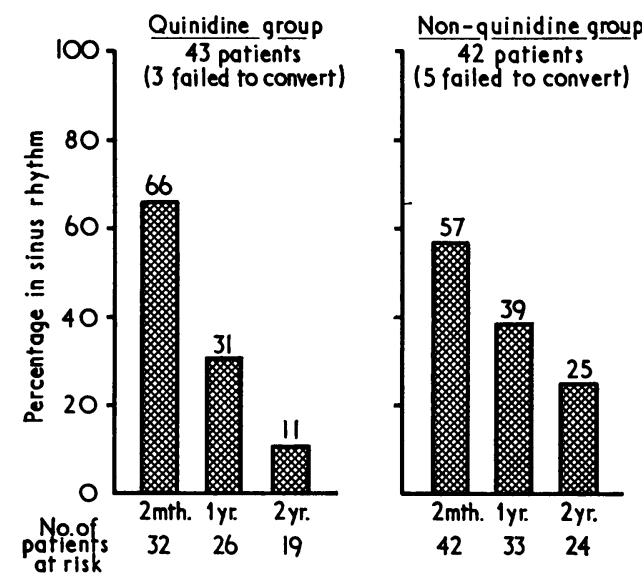

FIG. 2 Number of patients remaining in sinus rhythm for the quinidine and nonquinidine groups at various times of follow-up.

patients remaining in sinus rhythm to the total followed up at the appropriate time. There is no significant difference between the 2 groups ( $p>0.2$ at all times). The over-all higher percentages of patients remaining in sinus rhythm at all times of follow-up in both these groups compared with the follow-up for the total series is due to the fact that the quinidine/non-quinidine trial figures are expressed as a percentage of those successfully converted, whereas in the total series figures are expressed as a percentage of all those in whom conversion was attempted and thus include the initial failures.

The results of the follow-up on those patients whose onset of atrial fibrillation occurred for the first time in the post-operative period are shown in Fig. 3. This group has a significantly higher percentage of patients remaining in sinus rhythm at all times of follow-up when compared with the patients who had atrial fibrillation pre-operatively ( $p<0.01$ at all times of follow-up).

\section{Discussion}

The initial success rate of cardioversion in this series, at 83 per cent of attempts, corresponds to the figures found by others. However, by 2 months only 50 per cent of the original patients remained in sinus rhythm. This figure had fallen to 25 per cent by I year and remained at $14-16$ per cent at 2 and 3 years, respectively (Fig. I). A 25 per cent figure at 4 years is based on only 4 patients. This rate of maintenance of sinus rhythm after attempted conversion of atrial fibrillation is somewhat lower than in most other series. Direct comparison is difficult because of varying methods of expressing results and selection of patients, but most series report 40-50 per cent of patients remaining in sinus rhythm at some period between 8 and 15 months (Selzer et al., 1965; Morris, Peter, and McIntosh, 1966; Oram and Davies, 1964; Hall and Wood, 1968; Halmos, 1966; Semer et al., 1967). Our figure of 25 per cent remaining in sinus rhythm at $I$ year is closer to that of 13 per cent at I year of Radford and Evans (1968). Their series also was confined to patients with rheumatic heart disease; but here there was a small number of patients. Indeed, as shown in Fig. 3, if only the patients with preoperative atrial fibrillation are included our incidence is only I5 per cent of patients remaining in sinus rhythm at I year.

All our patients had chronic rheumatic heart disease, had had corrective cardiac surgery performed, and the onset of atrial fibrillation had occurred within the preceding 24 months.

Patients were not specifically excluded on the basis of a large left atrium though this has been shown to be prognostically unfavourable (Semer et al., 1967). However, exclusion of patients with atrial fibrillation of longer than 24 months virtually eliminated all patients with very large atria. The length of follow-up is longer than in most other series, and it appears from our results that there is little chance of relapse to atrial fibrillation after conversion has been maintained for 2 years.

Far better results in patients in whom atrial fibrillation began during the post-operative period have been reported by Selzer et al. (1965) and by Radford and Evans (1968). Our findings are in agreement (Fig. 3). The initial

FIG. 3 Number of patients remaining in sinus rhythm according to the time of onset of atrial fibrillation. Statistically significant difference at all times of follow-up $(p<0.01)$.

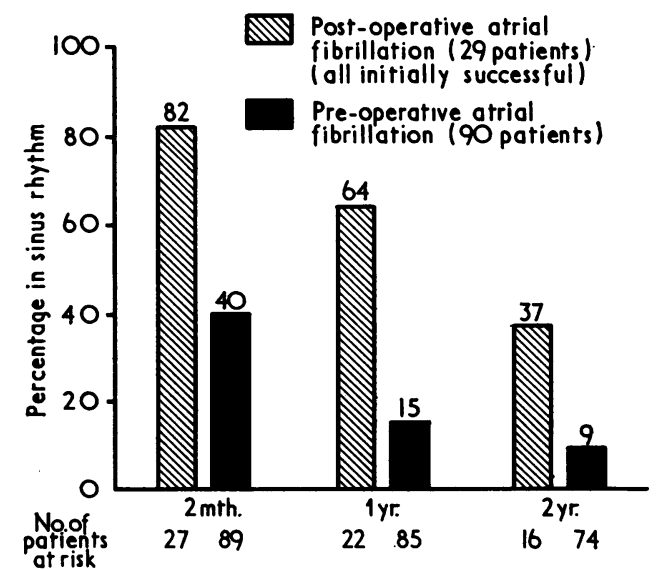


success rate of conversion was 100 per cent; at 2 months 82 per cent of patients remained in sinus rhythm, and at 12 months 64 per cent were still in sinus rhythm.

The disappointing regularity with which our patients with pre-operative atrial fibrillation reverted to atrial fibrillation after successful cardioversion leads us to question the value of post-operative cardioversion even when the onset of atrial fibrillation is recent. We suggest, like Radford and Evans (1968), that there is little place for post-operative cardioversion in such patients.

By contrast, the more satisfactory long-term results when atrial fibrillation has occurred for the first time in the post-operative period indicate that it is well worth while converting these patients to sinus rhythm. However, such patients have been frequently observed to convert spontaneously to sinus rhythm (Halmos, 1966; Selzer et al., 1965).

The use of quinidine to help to maintain sinus rhythm is still controversial. Many authors recommend that it be used prophylactically (Sokolow and Perloff, 196r; Lown et al., I963; Hurst et al., 1964; Selzer et al., 1965; Reinikainen et al., 1965; Morris et al., 1966; Semer et al., 1967; Fisher, Mason, and Morrow, 1968), while others state that it has no effect in prolonging the duration of sinus rhythm (Halmos, 1966; Szekely et al., 1966; Resnekov et al., 1968). Hall and Wood (1968), in a controlled trial in patients with rheumatic heart disease, showed that quinidine did not increase the duration of sinus rhythm after successful conversion. Some authors, who started a trial of prophylactic quinidine, stopped after a short time because of sudden deaths in patients on quinidine (Oram and Davies, I964; Halmos, 1966; Radford and Evans, 1968).

Our results show no significant difference in the percentage of patients remaining in sinus rhythm at 2 months, I year, and 2 years, respectively, after conversion, in the quinidine and non-quinidine groups (Fig. 2). There is also no significant difference in the initial success rate of conversion in either group. The fact that the quinidine group contained ro patients with post-operative onset of atrial fibrillation, and the non-quinidine group I4 patients, would only slightly bias the non-quinidine group towards a better prognosis. Furthermore, $4 \mathrm{I}$ of the patients in the quinidine group had operations on the mitral valve compared with 33 in the non-quinidine group. This imbalance occurred in spite of our method of random selection into either group. However, since all patients had chronic rheumatic heart disease we have assumed that the prognosis would be similar. This assumption could not be confirmed, however, since the number with aortic valve surgery alone was small and the majority of these patients fell into the group with post-operative onset of atrial fibrillation, which we and others have shown to have a better prognosis for maintenance of sinus rhythm. There were no episodes of sudden death in our patients taking quinidine, but this hazard in a small number of patients is well known (Thomson, 1956; Oram and Davies, 1964).

We do not, therefore, recommend the use of quinidine to maintain sinus rhythm after successful conversion of atrial fibrillation to sinus rhythm.

We thank Professor J. F. Goodwin and Dr. C. M. Oakley for their encouragement and advice in the preparation of this work.

\section{References}

Fisher, R. D., Mason, D. T., and Morrow, A. G. (I968). Restoration of sinus rhythm after mitral valve replacement. Correlations with left atrial pressure and size. Circulation, 37, Suppl. 2, 173.

Hall, J. I., and Wood, D. R. (1968). Factors affecting cardioversion of atrial arrhythmias with special reference to quinidine. British Heart fournal, 30, 84 .

Halmos, P. B. (1966). Direct current conversion of atrial fibrillation. British Heart fournal, 28, 302.

Hurst, J. W., Paulk, E. A., Proctor, H. D., and Schlant, R. C. (1964). Management of patients with atrial fibrillation. American fournal of Medicine, 37, 728.

Lown, B., Perlroth, M. G., Kaidbey, S., Abe, T., and Harken, D. E. (I963). 'Cardioversion' of atrial fibrillation. A report on the treatment of 65 episodes in 50 patients. New England fournal of Medicine, 269, 325.

Morris, J. J., Jr., Peter, R. H., and McIntosh, H. D. (I966). Electrical conversion of atrial fibrillation: Immediate and long-term results and selection of patients. Annals of Internal Medicine, 65, 216.

Oram, S., and Davies, J. P. H. (1964). Further experience of electrical conversion of atrial fibrillation to sinus rhythm: analysis of 100 patients. Lancet, $\mathbf{r}$, 1294.

Radford, M. D., and Evans, D. W. (1968). Long-term results of DC reversion of atrial fibrillation. British Heart fournal, 30, 91.

Reinikainen, M., Koskinen, P., Pöntinen, P., and Siitonen, L. (1965). Experiences in the use of direct current countershock in the treatment of cardiac arrhythmias. Acta Medica Scandinavica, 178, Suppl. 437.

Resnekov, L., Waich, S., Gibson, D., and McDonald, L. (I968). The use of long acting quinidine in maintaining sinus rhythm following electro conversion of atrial dysrhythmias. Communication to British Cardiac Society 1968.

Rossi, M., and Lown, B. (1967). The use of quinidine in cardioversion. American fournal of Cardiology, 19, 234.

Selzer, A., Kelly, J. J., Gerbode, F., Kerth, W. J., Blackley, J. E., Morgan, J. J., and Keyani, K. (1965). Treatment of atrial fibrillation after surgical repair of the mitral valve. Annals of Internal Medicine, 62, 1213. 
Semer, H., Hultgren, H., Kleiger, R., and Braniff, B. (1967). Cardioversion following prosthetic mitral valve replacement. Circulation, 35, 523.

Sokolow, M., and Perloff, D. B. (I96I). The clinical pharmacology and use of quinidine in heart disease. Progress in Cardiovascular Diseases, 3, 316.
Szekely, P., Batson, G. A., and Stark, D. C. C. (1966). Direct current shock therapy of cardiac arrhythmias. British Heart fournal, 28, 366.

Thomson, G. W. (1956). Quinidine as a cause of sudden death. Circulation, 14, 757. 